\title{
WEATHERING OF ROCK AS ARMOURSTONE: A CASE STUDY ON BAHRAIN LIMESTONE
}

\begin{abstract}
Andrea Caricato $^{1}$, Leo Woods ${ }^{1}$ and Chandra Mohan ${ }^{1}$
Locally-sourced armourstone is used extensively in the construction of new sea defence structures throughout Bahrain, with hundreds of thousands of tonnes being placed on single reclamation projects. This armourstone is won almost exclusively from the local quarry, which outputs limestone of variable quality. An evaluation has been made into the quality of local rock for usage as armourstone, using observations on sites and at the quarry, as well as compliance test results from various projects undertaken in recent years. Attempts are made to quantify potential losses in-service, by using the two degradation models described in the CIRIA Rock Manual, which give markedly different estimates. The envisaged loss of mass is difficult to predict with great accuracy due to the high sensitivity of the models to material and site parameters. Plots of estimated mass loss over time are presented for different rock sizes and different levels of rock armour mobility.
\end{abstract}

Keywords: armourstone; degradation; weathering; micro-deval; armourstone quality designation; Bahrain.

\section{INTRODUCTION}

The Kingdom of Bahrain is an island state located within the Gulf of Salwa, a part of the Persian Gulf. Like many Gulf States, Bahrain is currently undertaking extensive shoreline developments, including several large reclamation projects, which involve the construction of tens of kilometres of new coastal defences.

Coastal defences in Bahrain are primarily rock armoured structures utilising locally-sourced rock won from the quarry (the only one in Bahrain) at Askar, which outputs limestone of variable quality. This paper describes a study conducted into the quality of this rock as a source of armourstone. The ultimate aim of this study is to quantify the reduction in armourstone mass which could be anticipated over the design life of a coastal structure, so that allowances could be made for this mass loss during the design stage.

Mathematical models to estimate weathering losses in-service have been developed in the past. The first work was proposed by Latham (1991), who presented a method for predicting armourstone mass loss in-service. Lienhart (1998) presented a method of evaluating the quality of armourstone sources. These researches were combined into two separate degradation models by Latham, Lienhart and Dupray in 2006 and these models were presented in the second edition of the CIRIA Rock Manual in 2007. Although using these methods is 'by its nature inexact and burdened with difficult judgments' (CIRIA 2007) they are considered to provide some benefit over human judgment alone, and both of these methods have been applied to Bahraini armourstone in this paper.

\section{GENERAL DESCRIPTION OF BAHRAINI ROCK}

It is noticeable that Bahraini rock is of variable quality, with differences being visually evident in terms of the colour of the rock, and the presence of vugs and other flaws in the rock fabric. Sometimes voids are evident in the rocks at the quarry and sometimes these pockets are filled with clay. Such examples are shown in Figure 1.

It has been suggested that vugs are not necessarily detrimental, and may even be beneficial to the durability of armour stone, provided that they are small and evenly distributed (Erickson, 1993). However, where these voids may form a failure plane or occupy a substantial part of the rock's volume they have an obvious ability to reduce the integrity of the block.

1 Scott Wilson Ltd., Euro Tower, Office 31, Bldg 485, Rd 1010, Sanabis 410. PO Box 18378, Manama, Kingdom of Bahrain. Tel+973.17556634, Fax+973.17550151. Email: andrea.caricato@scottwilson.com 

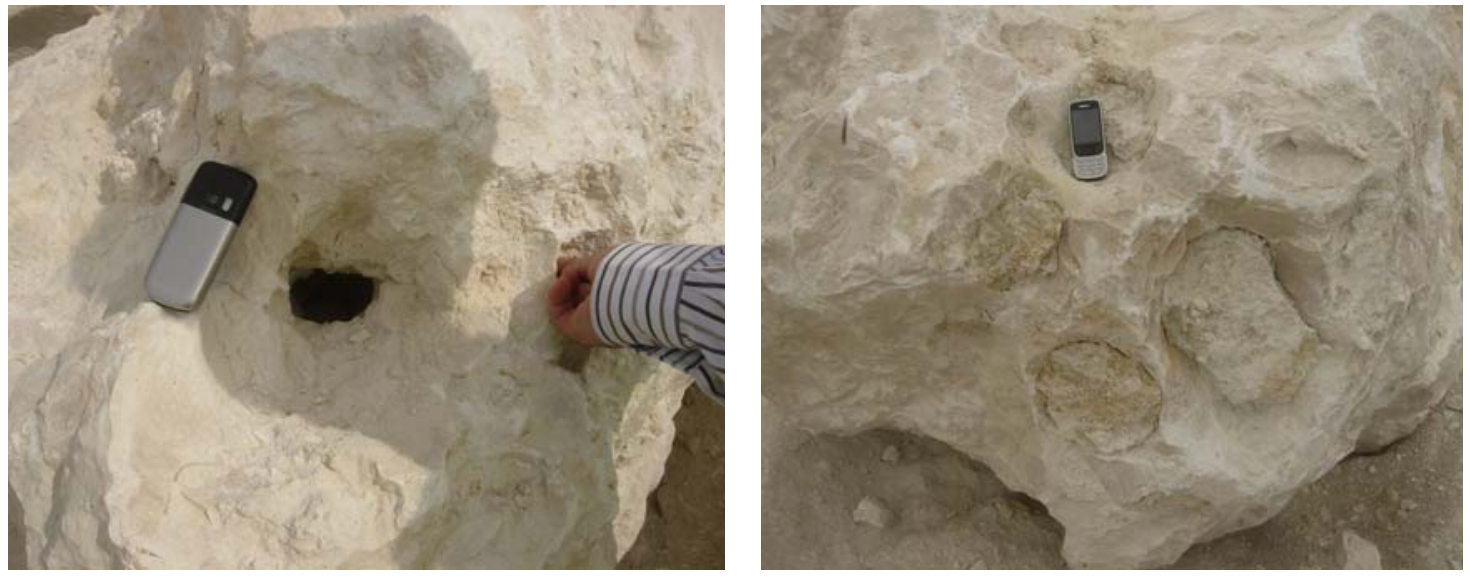

Figure 1. Examples of rocks containing voids (left) and clay pockets (right).

Inspection of revetments which have been in-service for a short period of time shows signs of surface crumbling in the supra-tidal zone, as shown in Figure 2.

The surface crumbling may be attributed to the quality of the rock and the extremely high temperatures and salinities in the region.

In the intertidal zone the more evident form of early weathering is pocketing, which is also apparent after a short period of time in-service. However, this is believed to be due to the washing out of clay pockets already present when the rock was placed and is probably not a concern in the long term.
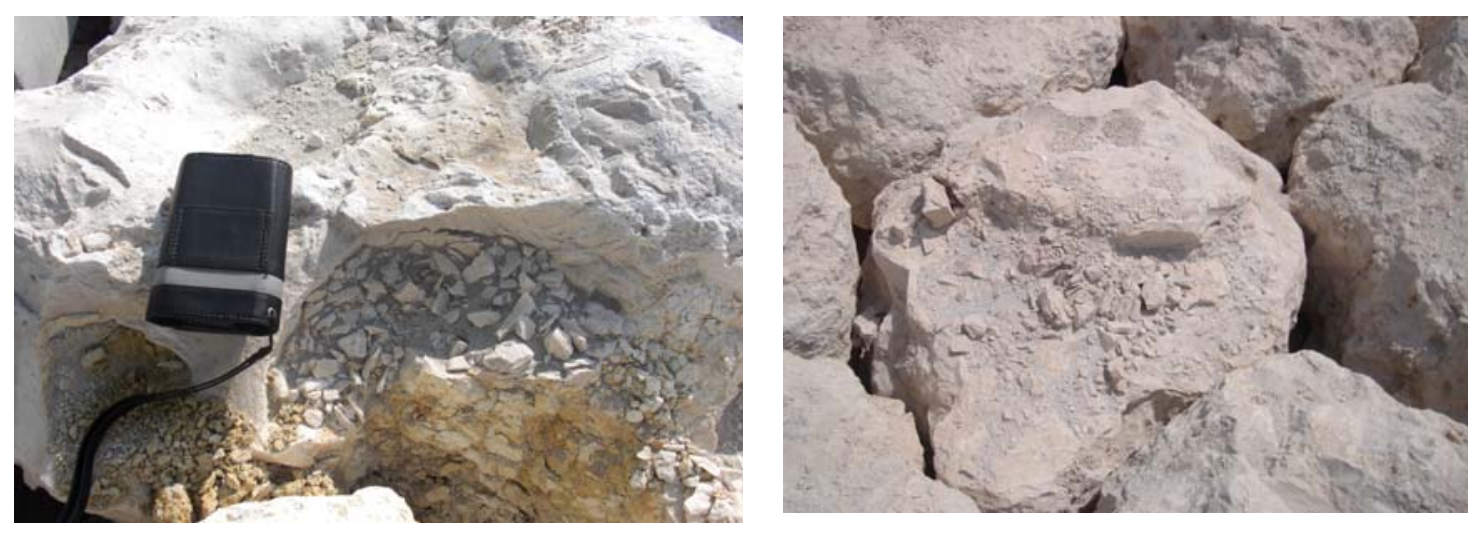

Figure 2. Examples of rocks showing surface crumbling after approximately three years in service.

It is evident that a significant amount of rock placed on revetments in Bahrain is broken during placement.

This is thought to be due to the rather weak and fissured nature of the rock, in combination with the fact that it is common in Bahrain to flatten the revetment surface with the back of an excavator to form a smooth and attractive surface.

Typical examples of rocks broken during placement are shown in Figure 3.

Although the drop test should provide an indication of the ability of the rock to resist major breakage, the test is intended to simulate rocks being dropped onto other rocks during construction, and is unlikely to be an accurate test of a rocks ability to withstand being beaten into place with an excavator shovel. 

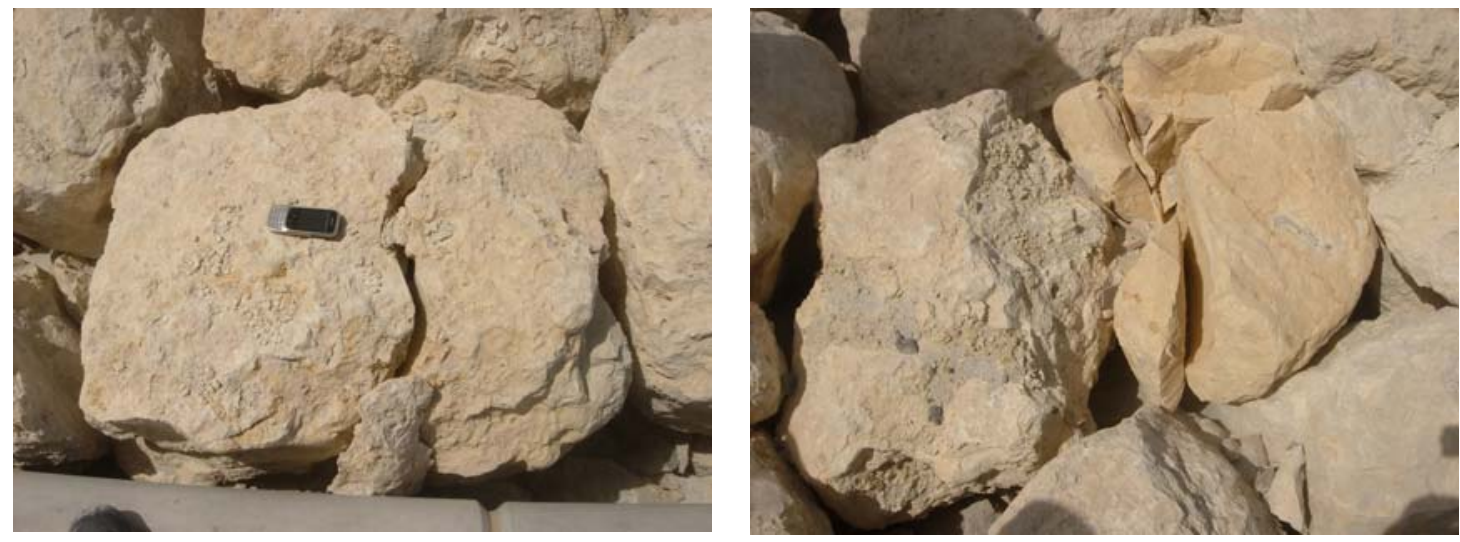

Figure 3. Examples of rocks which have been broken during placement.

\section{AVAILABLE INFORMATION}

Since a number of large shore protection works have been undertaken in recent years, there is a reasonable amount of information available on rock quality based on tests undertaken to prove compliance with specifications. A summary of available results is given in Table 1.

\begin{tabular}{|l|c|c|c|}
\hline Table 1. Available Test Results & Noan Value \pm Standard Deviation & of Tests & Rating by CIRIA \\
\hline Propriety & $2.58 \pm 0.08$ & 970 & Good \\
\hline Dry Density $\left(\mathrm{t} / \mathrm{m}^{3}\right)$ & $2.09 \pm 1.25$ & 970 & Marginal \\
\hline Water Absorption (\%) & $59.3 \pm 24.3$ & 93 & Poor \\
\hline Compressive Strength (MPa) & $5.88 \pm 1.06$ & 107 & Good \\
\hline Point Load Index & $30.1 \pm 4.2$ & 38 & Marginal \\
\hline Los Angeles (\%) & $3.89 \pm 2.87$ & 107 & Good \\
\hline MgSO $_{4}$ Soundness (\%) & $2.56 \pm 1.45$ & 29 & Good \\
\hline Drop Test (\%) & & & \\
\hline
\end{tabular}
2.

Field based indicators of rock quality were assessed at the Askar Quarry and are summarised in Table

\begin{tabular}{|l|c|c|}
\hline Table 2. Field Based Indicators & Rating by CIRIA \\
\hline Criteria & Argillaceous Limestone & Marginal \\
\hline Lithological Classification & II - Slightly Weathered & Marginal \\
\hline Weathering Grade & Completely Dry & Marginal \\
\hline Groundwater Condition & Conventional Blasting & \multirow{2}{*}{ Marginal } \\
\hline Production Method & $10-15 \%$ of stones LT>3 & Marginal \\
\hline Stone Shape \& Weathering Grade & $95 \%$ of stones Grade II & Approx. 1 month \\
\hline Set Aside & & \\
\hline
\end{tabular}

The Rock Manual indicates that density variation is a good indication of overall quality variation, and that the difference between the average and the $90 \%$ exceedance density should generally be not more than $100 \mathrm{~kg} / \mathrm{m}^{3}$. Assessment of the 970 density tests which are available yields a $90 \%$ exceedance density of $2.48 \mathrm{t} / \mathrm{m}^{3}$, which is exactly $100 \mathrm{~kg} / \mathrm{m}^{3}$ below the mean density, and so at the limit of the normal range suggested by CIRIA. This suggests that the variability of rock produced at Askar is high, which concurs with observations at the quarry and on site. 


\section{OVERVIEW OF DEGREDATION MODELS}

The Rock Manual describes two methods, the Micro-Deval (MDE) Method, and the Armourstone Quality Designation (AQD) Method. These two degradation models are greatly based on works carried out by Latham (1991) and Leinhart (1998 and 2003), which were later redeveloped (Latham, Lienhart, Dupray, 2006).

Both of these models calculate a parameter which represents the site aggressiveness (the Equivalent Wear Time Factor, $\mathrm{X}$ ) and a parameter which represents the intrinsic durability of the rock (the Intrinsic Resistance to Mass Loss, $\mathrm{k}_{\mathrm{s}}$ ) and use them to estimate mass loss over time with Equation 1.

$$
\frac{M}{M_{0}}=0.05 \exp \left[-30\left(\frac{k_{S} T}{X}\right)\right]+0.95 \exp \left[\frac{-k_{S} T}{X}\right]
$$

Where $\mathrm{M}=$ nominal mass of armourstone at time $\mathrm{T}$;

$\mathrm{M}_{0}=$ initial mass of armourstone;

$\mathrm{k}_{\mathrm{S}}=$ intrinsic resistance to mass loss;

$\mathrm{X}=$ equivalent wear time factor;

$\mathrm{T}=$ time since installation (years).

The intrinsic resistance to mass loss $\mathrm{k}_{\mathrm{s}}$ is a property intrinsic to the rock material describing the resistance to weathering and the method of calculation is different for the two models.

For the Micro-Deval method it is solely related to the Micro-Deval Coefficient, whereas for the AQD method a number of indicators of rock quality are combined with a weighted average system. The AQD method therefore takes account of a much greater number of relevant factors when assessing $\mathrm{k}_{\mathrm{s}}$ and for this reason it may be preferred. However, the MDE method is probably better calibrated and the Rock Manual recommends that the results of both methods should be considered together.

The Equivalent Wear Time Factor, $\mathrm{X}$, reflects the rock size, grading, shape and the conditions that the rock is subject to (wave conditions, climate, waterborne attrition, etc) and it is obtained by a similar method for both the MDE and the AQD method. Nine parameters, designated $\mathrm{X}_{1}$ to $\mathrm{X}_{9}$, represent the various factors affecting weathering rates on site, e.g. wave impact $\left(\mathrm{X}_{4}\right)$, climatic weathering $\left(\mathrm{X}_{6}\right)$, waterborne attrition agents $\left(\mathrm{X}_{7}\right)$, etc. The values for these parameters are obtained from look-up tables based on properties such as significant wave height, climate statistics, type of waterborne attrition agent, etc, and in the case of the MDE method, also properties of the rock, such as the block integrity and water absorption. Finally, the overall Equivalent Wear Time Factor is calculated as the product of each of these parameters as per Equation 2.

$$
X=X_{1} \times X_{2} \times X_{3} \times X_{4} \times X_{5} \times X_{6} \times X_{7} \times X_{8} \times X_{9}
$$

\section{MICRO-DEVAL COEFFICIENT}

The Micro-Deval test is a test of a rock's resistance to abrasion. The test procedure involves tumbling a sample of 10-14mm aggregate (obtained by crushing representative armourstone) in a standard drum with a controlled quantity of water and steel balls for a standard period of time. The result of the test, the Micro-Deval Coefficient $\left(\mathrm{M}_{\mathrm{DE}}\right)$, is the percentage by mass of material which passes a $1.6 \mathrm{~mm}$ sieve on completion of the tumbling process. The test is outlined definitively in BS EN1097-1.

Since the Micro-Deval test result is essential to the application of the MDE method, and also has some (much more limited) influence on the AQD method, it was necessary to obtain an indicative Micro-Deval coefficient for Bahraini rock.

The Micro-Deval test is unfortunately not commonly undertaken on Bahraini rock and it is thought that there are no testing laboratories capable of undertaking the test in the region. Another mill abrasion test - the Los Angeles test - is commonly undertaken in the Kingdom, but studies in the past have found no 
significant correlation between the Los Angeles and the Micro-Deval test result (Rangaraju and Edlinski, 2008).

A number of samples were taken from the Askar quarry and sent to a laboratory in the UK for testing. The samples were taken from various parts of the quarry and of varying quality (as assessed visually), but unfortunately some sample bags were broken in transit, resulting in mixing of the aggregates. As a result just four Micro-Deval tests were undertaken - two on unbroken sample bags and two on the mixed sample material. These values were tentatively applied to degradation modelling, but treated with considerable caution there were so few tests and because of the mixing of the samples.

\section{METEOROLOGICAL CLIMATE WEATHERING INTENSITY}

One area in which the CIRIA guidance appears to be not entirely suitable for estimating rock weathering rates in the Middle East is in its recommendations to determine the parameter $\mathrm{X}_{6}$, which is representative of the aggressiveness of the meteorological climate.

The recommendation is to use the Meteorological Climate Weathering Intensity (MCWI) index presented by Lienhart (2003), and reproduced in Equation 3. This value is used (along with the water absorption, in the case of the MDE method) to look up values for $\mathrm{X}_{6}$. However, this parameter is based on NOAA data from the United States only, and is not considered to be suitable for the Persian Gulf. In fact, since the MCWI index is calculated based on the mathematical product of a number of parameters, and one of these is the number of days when the temperature falls below freezing (which does not occur in Bahrain) the MCWI calculated in this way must be zero and the climate is treated as benign.

$$
M C W I=(\mathrm{a} / \mathrm{b}) \times(\mathrm{d} / 365) \times(\mathrm{e} / \mathrm{c}) \times((\mathrm{g} / \mathrm{f}) \times \mathrm{h})
$$

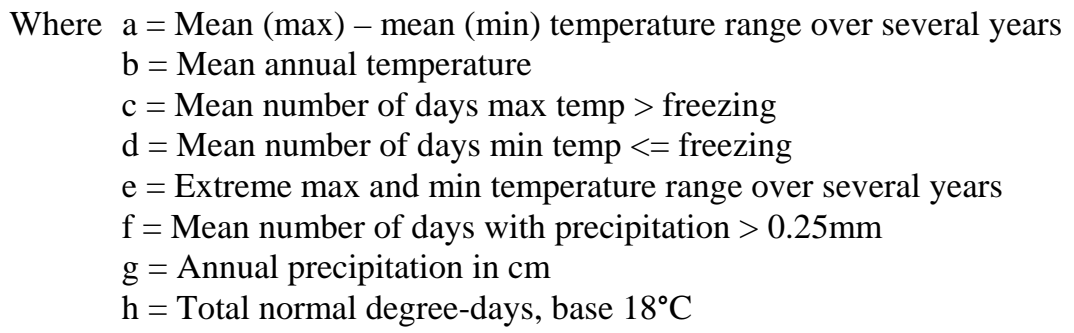

It was noted in Latham's paper (Latham 1991) that salt crystallization in porous sedimentary rocks can be accelerated by the climate in the Middle East, and this concurs with observations of armourstone inservice in Bahrain. Therefore, the original recommendations from Latham were used to determine $\mathrm{X}_{6}$ instead of the MCWI index of Lienhart.

This decision has a considerable impact on the final estimates; $\mathrm{X}_{6}$, which would have been 0.8 (MDE) or 1.0 (AQD) if the MCWI method was used, is instead 0.2, and therefore the Equivalent Wear Time Factor would have been 4 or 5 times higher if the MCWI method proposed by CIRIA had been adopted. For a typical Bahraini rock, this could result in the final degradation estimate can double if the MCWI method were used instead of Latham's method.

Indeed, even if Latham's method is applied the $\mathrm{X}_{6}$ parameter is somewhat sensitive, as it is 0.2 where the water absorption is above $2 \%$ and 0.5 when the water absorption is below $2 \%$. Since the water absorption is estimated to be $2.09 \%$, Bahraini rock is on the borderline, but nevertheless a value of 0.2 has been adopted. 


\section{DETERMINATION OF THE INTRINSIC RESISTANCE TO MASS LOSS}

As described above, $\mathrm{k}_{\mathrm{s}}$ is obtained by a different method depending on whether the MDE or the AQD method is being used. For the MDE method, it is simply obtained from the Micro-Deval coefficient $\mathrm{M}_{\mathrm{DE}}$ using equation 4.

$$
k_{s}=4.12 \times 10^{-5} M_{D E}^{1.485}
$$

In light of the uncertainty in the Micro-Deval results which have been obtained consideration needs to be given to the $M_{D E}$ value which is to be applied to obtain $k_{s}$. The $M_{D E}$ values obtained were both $16 \%$ for the two mixed samples, $19 \%$ for the sample representative of rock appearing to be good quality and $32 \%$ for the sample of apparently poor quality rock. If the range $16 \%$ to $32 \%$ is assumed to be representative of Bahraini armourstone then this gives $\mathrm{k}_{\mathrm{s}}$ of $2.52 \times 10^{-3}$ to $7.08 \times 10^{-3}$.

The method for determining the $\mathrm{k}_{\mathrm{s}}$ value when using the AQD Method is somewhat more complicated, involving a weighted average of a number of factors.

The same weights have been applied as recommended by the Rock Manual to obtain the AQD value, and this calculation is shown in Table 3.

Table 3. Estimate of AQD value

\begin{tabular}{|c|c|c|c|c|c|c|}
\hline & No. & Criteria & Description & Rating & $\begin{array}{l}\text { Weight } \\
(\%)\end{array}$ & $\begin{array}{l}\text { Weighted } \\
\text { Rating }\end{array}$ \\
\hline \multirow{9}{*}{ 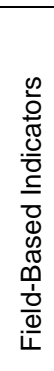 } & 1 & Lithological Classification & Argillaceous limestone (MARGINAL) & 2.0 & 58 & 1.44 \\
\hline & 2 & Regional In-Situ Stress & Not considered & - & - & - \\
\hline & 3 & Weathering Grade & $\begin{array}{l}\text { Grade II - Slightly Weathered } \\
\text { (MARGINAL) }\end{array}$ & 2.0 & 73 & 1.81 \\
\hline & 4 & Discontinuity Analysis & Not Considered & - & - & - \\
\hline & 5 & Groundwater Condition & Completely Dry (EXCELLENT) & 4.0 & 73 & 3.63 \\
\hline & 6 & Production Method & Conventional Blasting (MARGINAL) & 2.0 & 95 & 2.36 \\
\hline & 7 & $\begin{array}{l}\text { Stone Shape \& } \\
\text { Weathering Grade }\end{array}$ & Not Considered & - & - & - \\
\hline & 8 & Set-Aside & One Month Assumed (MARGINAL) & 2.0 & 73 & 1.81 \\
\hline & 9 & Petrographic Evaluation & Not Considered & - & - & - \\
\hline \multirow{2}{*}{1} & 10 & Block Integrity Test & $I_{M 50}=2.56(G O O D)$ & \multirow{2}{*}{3.0} & \multirow{2}{*}{90} & \multirow{2}{*}{3.35} \\
\hline & 11 & Block Integrity Visual & Not Considered & & & \\
\hline \multirow{4}{*}{2} & 12 & Mass Density & $2.58 \mathrm{t} / \mathrm{m}^{3}(\mathrm{GOOD})$ & \multirow{4}{*}{2.5} & \multirow{4}{*}{80} & \multirow{4}{*}{2.48} \\
\hline & 13 & Water Absorption & $2.09 \%$ (MARGINAL) & & & \\
\hline & 14 & $\begin{array}{l}\text { Microporosity/Total } \\
\text { Porosity }\end{array}$ & Not Considered & & & \\
\hline & 15 & Methylene Blue Absorption & Not Considered & & & \\
\hline \multirow{3}{*}{3} & 16 & Compressive Strength & $59.3 \mathrm{MPa}(\mathrm{POOR})$ & \multirow{3}{*}{1.0} & \multirow{3}{*}{88} & \multirow{3}{*}{1.09} \\
\hline & 17 & Schmidt Impact Index & Not Considered & & & \\
\hline & 18 & Sonic Velocity & Not Considered & & & \\
\hline \multirow{3}{*}{4} & 19 & Point Load Strength & $5.88 \mathrm{MPa}(\mathrm{GOOD})$ & \multirow{3}{*}{2.5} & \multirow{3}{*}{88} & \multirow{3}{*}{2.73} \\
\hline & 20 & Fracture Toughness & Not Considered & & & \\
\hline & 21 & Los Angeles & $30.1 \%$ (MARGINAL) & & & \\
\hline 5 & 22 & Micro-Deval & $16 \%$ (GOOD) to $32 \%$ (POOR) & $\begin{array}{c}1.0 \text { to } \\
3.0\end{array}$ & 88 & $\begin{array}{c}1.09 \text { to } \\
3.26\end{array}$ \\
\hline \multirow{4}{*}{6} & 23 & Freeze-Thaw Loss & Not Considered & \multirow{3}{*}{3.0} & \multirow{3}{*}{80} & \multirow{3}{*}{2.98} \\
\hline & 24 & $\mathrm{MgSO}_{4}$ Soundness & $3.89 \%(G O O D)$ & & & \\
\hline & 25 & Wet-dry Loss & Not Considered & & & \\
\hline & & & Average & & 81 & $\begin{array}{l}2.25 \text { to } \\
2.42\end{array}$ \\
\hline
\end{tabular}

The AQD values so obtained are then converted into $\mathrm{k}_{\mathrm{s}}$ with Equation 5 to obtain $\mathrm{k}_{\mathrm{s}}=5.46 \times 10^{-3}$ to $6.32 \times 10^{-3}$. 


$$
k_{s}=0.032 A Q D^{-2.0}
$$

One of the great advantages of the AQD method is that properties which are not available from field evaluations and laboratory tests do not need to be included in the determination of the AQD value, and the weighted average AQD value can be based on whichever parameters are available.

Of course, the more parameters that are available the more accurate will be the estimate of the AQD value, and therefore the subsequent estimation of rock mass loss over time.

\section{DETERMINATION OF EQUIVILENT WEAR TIME FACTOR}

The assumptions made to estimate the Equivalent Wear Time Factor are summarised in Table 4.

Table 4. Estimate of the Equivalent Wear Time Factor, $X$

\begin{tabular}{|c|c|c|c|}
\hline \multirow{2}{*}{ Criteria } & \multirow{2}{*}{ Description } & \multicolumn{2}{|c|}{ Value } \\
\hline & & MDE & AQD \\
\hline$X_{1}$ (Rock Size) & $\begin{array}{l}\text { Considered typical primary armour in Bahrain of between: } 0.5 \text { and } 3.0 \\
\text { tonnes. }\end{array}$ & $\begin{array}{l}0.40 \text { to } \\
0.72\end{array}$ & $\begin{array}{l}0.40 \text { to } \\
0.72\end{array}$ \\
\hline $\mathrm{X}_{2}$ (Rock Grading) & Narrow graded armour is assumed, with $\left(\mathrm{M}_{85} / \mathrm{M}_{15}\right)^{1 / 3} \approx 1.2$ & 1.2 & 1.2 \\
\hline $\mathrm{X}_{3}$ (Rock Shape) & Assumed Semi-Rounded based on inspection & 1.5 & 1.5 \\
\hline $\mathrm{X}_{4}$ (Wave Energy) & $\begin{array}{l}\text { The } 1 \text { in } 50 \text { year } \mathrm{H}_{\mathrm{s}} \text { is estimated to be approximately } 2.5 \mathrm{~m} \text { for } \\
\text { Bahrain's north coasts. Based on such small waves a value of } 4.0 \text { is } \\
\text { deemed reasonable. }\end{array}$ & 4.0 & 4.0 \\
\hline $\mathrm{X}_{5}$ (Zone of Structure) & Assumed worst case (intertidal) & 1.0 & 1.0 \\
\hline $\mathrm{X}_{6}$ (Climate) & $\begin{array}{l}\text { Used recommendations from Latham (1991) instead of CIRIA (2007). } \\
\text { Assumed to be a hot and dry climate with water absorption }>2 \%\end{array}$ & 0.2 & 0.2 \\
\hline $\begin{array}{l}\mathrm{X}_{7} \text { (Waterborne } \\
\text { Attrition) }\end{array}$ & $\begin{array}{l}\text { Would generally be no waterborne attrition agents due to mild wave } \\
\text { conditions, but the case of waterborne attrition by sand has also been } \\
\text { considered (the seabed around Bahrain comprises sand and silt. }\end{array}$ & $\begin{array}{l}1.0 \text { to } \\
1.5\end{array}$ & $\begin{array}{l}1.0 \text { to } \\
1.5\end{array}$ \\
\hline $\begin{array}{l}\mathrm{X}_{8} \text { (Concentration of } \\
\text { Wave Attack) }\end{array}$ & $\begin{array}{l}\text { Revetment slope angle is commonly } 1 \text { in } 2.5 \text { or gentler. Tidal range is } \\
\text { generally less than } 2 \mathrm{~m} \text { throughout the island }\end{array}$ & 1.0 & 1.0 \\
\hline $\begin{array}{l}\mathrm{X}_{9} \text { (Mobility of } \\
\text { Armourstone) }\end{array}$ & $\begin{array}{l}\text { Assumed static design concept (generally the case for permanent } \\
\text { structures in Bahrain), assuming } I_{\mathrm{m} 50}=2.56 \%\end{array}$ & 2.0 & 1.5 \\
\hline $\mathbf{X}$ & & $\begin{array}{l}1.15 \text { to } \\
3.11\end{array}$ & $\begin{array}{c}0.86 \text { to } \\
2.33\end{array}$ \\
\hline
\end{tabular}

\section{COMPARISON BETWEEN DEGREDATION MODELS}

The value ranges obtained above for the Intrinsic Resistance to Mass Loss and the Equivalent Wear Time Factor were input to Equation 1 to obtain likely degradation envelopes shown in Figure 4, for 1.5 tonne armour.

The two methods show plausible estimates of degradation over time, although the MDE Methods lowend estimates of mass loss do not seem likely.

This is due the lower values of the Micro-Deval coefficient indicating a rock of 'GOOD' quality. The AQD Method suggests the rock is of 'MARGINAL' quality.

In light of limited confidence in the Micro-Deval coefficient values which were obtained and the high sensitivity of the MDE Method to this test value, it is considered that the AQD model provides the more reliable estimates in this case.

This viewpoint is re-enforced by engineering judgement, which would suggest that a 'MARGINAL' quality rating as suggested by the AQD Method is a reasonable assessment of Bahraini rock.

The following analyses therefore consider the AQD Method in isolation. 


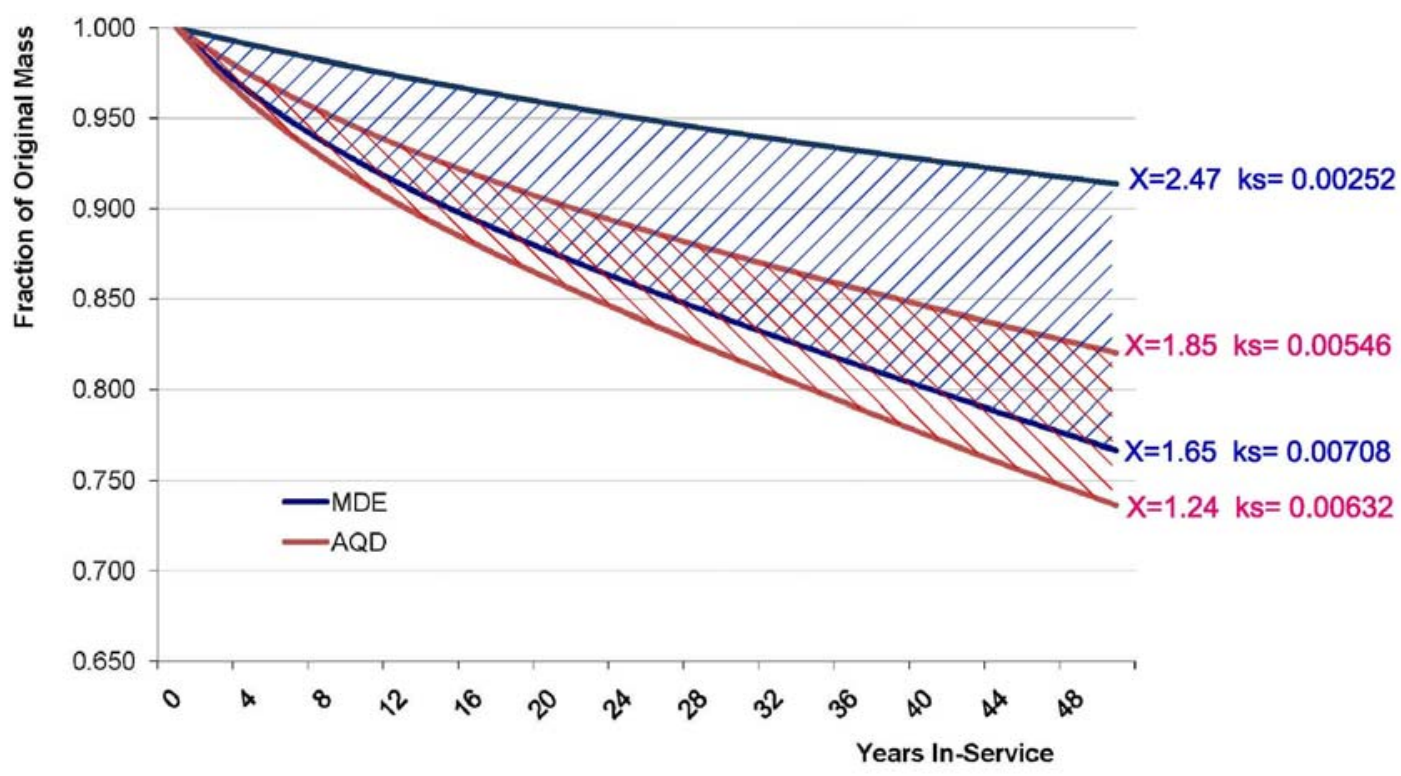

Figure 4. Likely degradation envelopes based for 1.5 tonne armour on the MDE and AQD Methods.

\section{EFFECT OF ROCK SIZE}

The rock size affects weathering rates, as the removal of a 'shell' of given thickness has a proportionately greater effect on a smaller rock than a larger one. Weathering rates are therefore greater in smaller rocks than in larger ones and this factor must be considered when making allowance for degradation in design.

Estimated degradation envelopes are shown in Figure 5 for three rock sizes which are typically used for primary armour in Bahrain; 0.5 tonnes $(X=0.86$ to 1.30$), 1.5$ tonnes $(X=1.24$ to 1.85 ) and 3.0 tonnes ( $\mathrm{X}=1.55$ to 2.33 ), using the AQD Method.

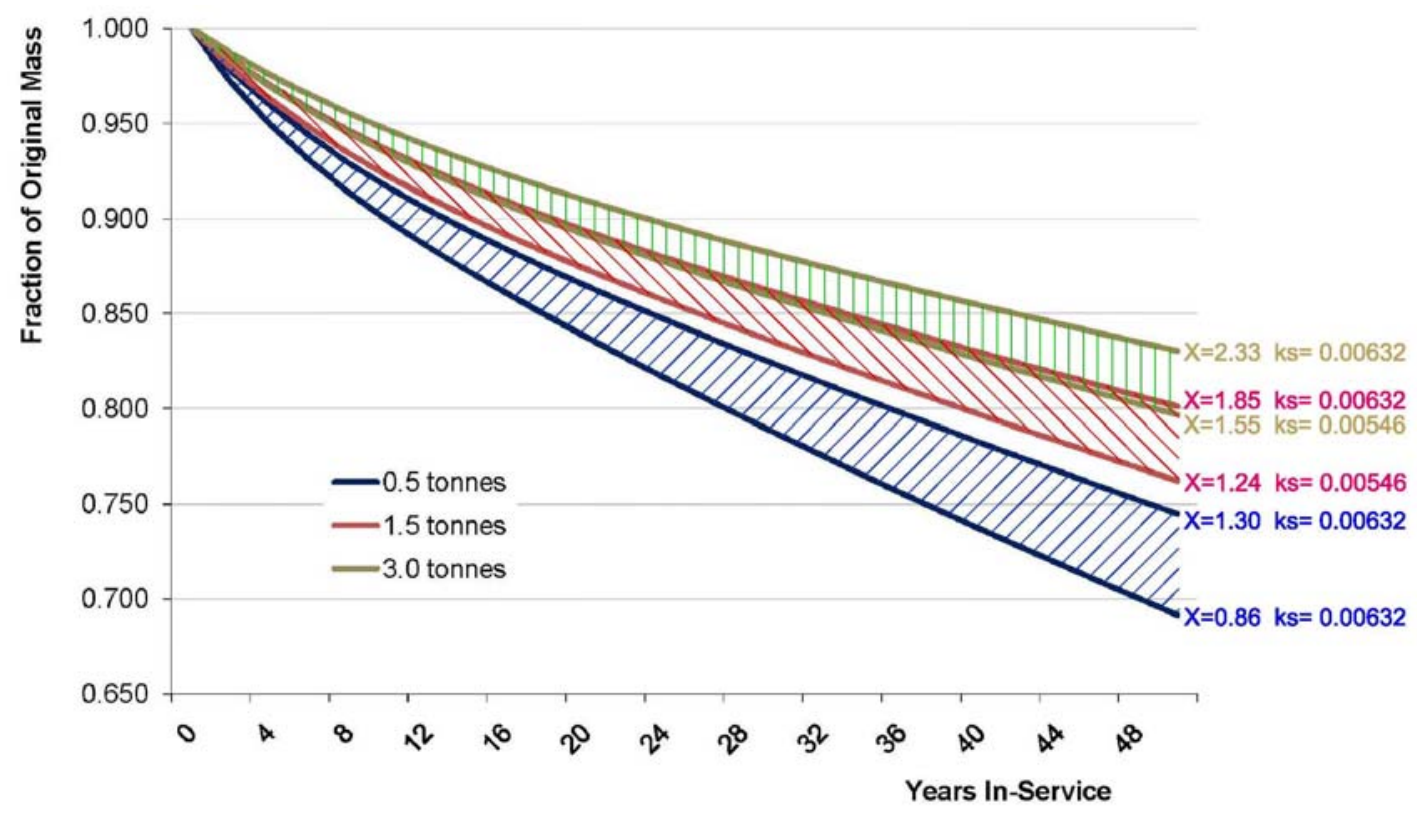

Figure 5. Likely degradation envelopes for different rock sizes based on the AQD Method. 
These degradation curves could provide indicative weathering allowances for the purposes of concept designs.

The final estimates of mass loss after a 50 year design life are summarised in Table 5.

Table 5. Fractions of original mass ranges calculated for Bahrain rock as armourstone in $\mathbf{5 0}$ years

\begin{tabular}{|c|c|}
\hline Initial rock size (M0) & $\begin{array}{c}\text { Fraction of original mass in } \\
\mathbf{5 0 y}\left(\mathbf{M} / \mathbf{M}_{\mathbf{0}}\right)\end{array}$ \\
\hline $0.5 \mathrm{t}$ & 0.69 to 0.75 \\
\hline $1.5 \mathrm{t}$ & 0.76 to 0.80 \\
\hline $3 \mathrm{t}$ & 0.80 to 0.83 \\
\hline
\end{tabular}

\section{EFFECT OF USING DYNAMIC DESIGN CONCEPT}

As mentioned in Table 4, a dynamic design concept is rarely used for permanent structures in Bahrain, but it is sometimes used for temporary designs. It is to be expected that dynamic structures will suffer more weathering as the movement of the reshaping of the structure requires individual rocks to move, resulting in increased rocking and block-to-block impacts and therefore increasing mass loss due to abrasion and breakage. A variety of degrees of mobility, expressed in terms of stability number $\mathrm{N}_{\mathrm{s}}=\mathrm{H}_{\mathrm{s}} / \Delta \mathrm{D}_{\mathrm{n} 50}$, are shown here for a 1.5 tonne rock.

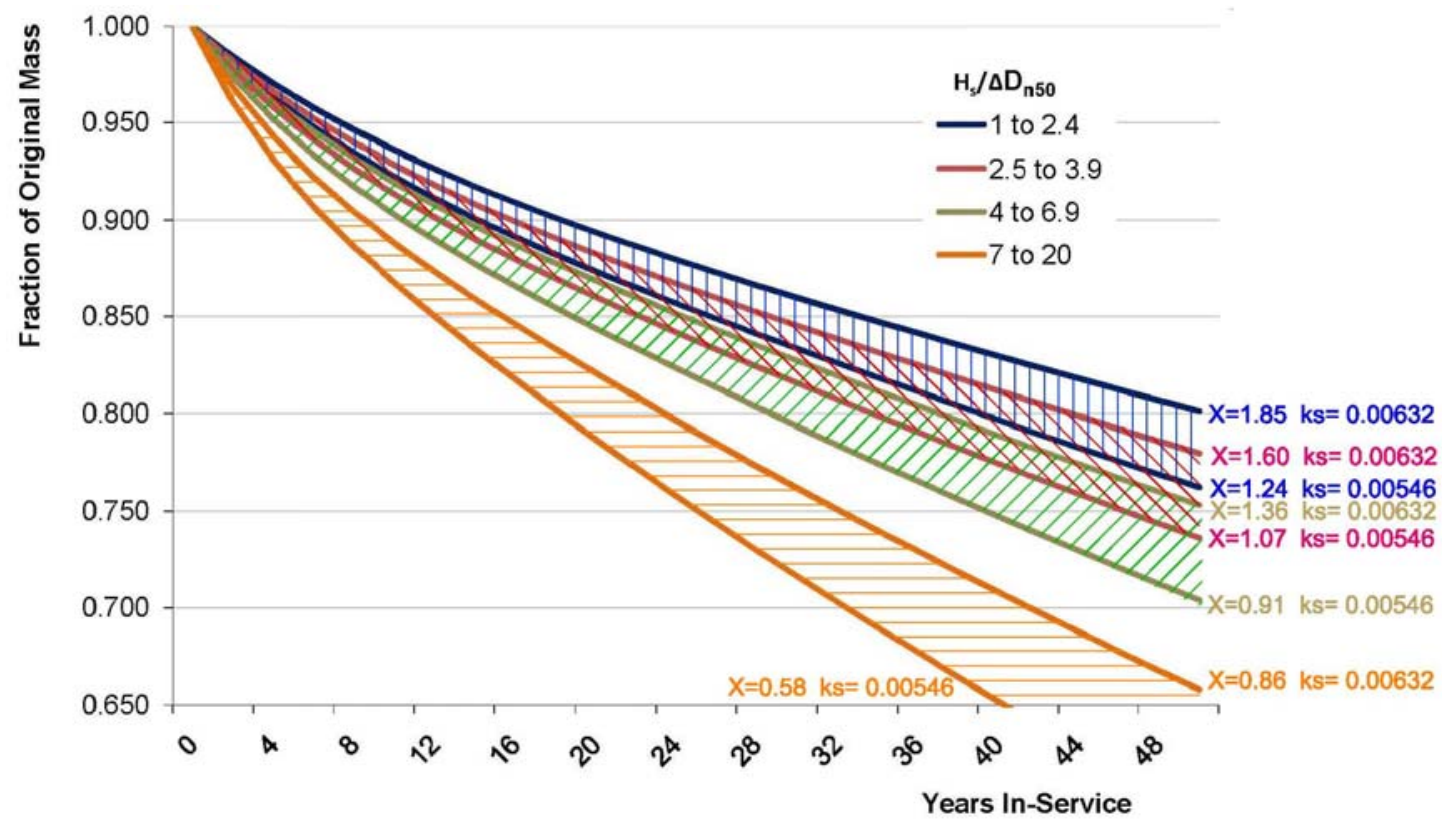

Figure 6. Likely degradation envelopes for different degrees of mobility for 1.5 tonne armour using AQD Method.

Where the rock is of known marginal quality (as is limestone produced by the quarry in Bahrain), the designers should therefore take into account the detrimental effect of selecting a high degree of mobility (or a high "damage factor" $S_{d}$ ), as this will accelerate the rock degradation.

Except for special applications or under particular circumstances (e.g. temporary structures, high maintenance regime accepted etc), it is recommended that marine structures utilising Bahraini rock should be designed as "statically stable" with a low damage factor $S_{\mathrm{d}}$. 


\section{CONCLUSIONS}

The rock produced at the local quarry is highly variable but could generally be described as marginal quality armourstone. The conditions that the rock is subject to are mild in terms of wave attack but the high salinities and temperatures in the region are likely to accelerate surface spalling and crumbling.

When the AQD and MDE models were applied to the known parameters for Bahraini rock, the MDE Method suggests lower degradation rates than the AQD Method. The results obtained on samples show significant variation in the resistance to wear. This is mainly due to the fact that the quality of the local rock varies within the same quarry.

This was confirmed by the density variation, described by CIRIA as a good indication of the overall quality variation.

Because the MDE method relies uniquely on the $\mathrm{M}_{\mathrm{DE}}$ coefficient for determining the intrinsic resistance to mass loss $k_{s}$, the results obtained adopting this method are to be treated with caution, as it relies entirely on the samples taken being truly representative of the output of the quarry.

On the other hand, the AQD method takes into account a number of different parameters, which are weighted and averaged to give the ADQ value used for the determination of $\mathrm{k}_{\mathrm{s}}$. Given the limited confidence in the Micro-Deval values obtained, it is considered that with the available data the AQD method provides a better general description of the rock resistance weathering in this case.

Based on the results of this model, it is suggested that concept designers should allow for $\mathrm{M} / \mathrm{M}_{0}$ of 0.69 for 0.5 tonne armour, 0.76 for 1.5 tonne armour and 0.80 for 3 tonne armour, for a 50 year design life (Table 6):

Table 6. Suggested fractions of original mass to be adopted for Bahrain rock as armourstone in $\mathbf{5 0}$ years

\begin{tabular}{|c|c|}
\hline Initial rock size $\left(M_{0}\right)$ & $\begin{array}{l}\text { Fraction of original mass in } \\
50 \mathrm{y}\left(\mathrm{M} / \mathrm{M}_{0}\right)\end{array}$ \\
\hline $0.5 \mathrm{t}$ & 0.69 \\
\hline $1.5 \mathrm{t}$ & 0.76 \\
\hline $3 t$ & 0.80 \\
\hline
\end{tabular}

The above figures have been determined adopting rock proprieties and site conditions which are deemed generally representative of the local rock and for the Bahrain coast. Designers should therefore carefully verify the applicability of these proposed degradation rates and refer to site-specific information in order to correctly apply the degradation models on a case-to-case basis.

For example design criteria (e.g. slope, grading envelope curves, stability number etc) could alter significantly the proposed degradation predictions. Likewise site conditions (e.g. tidal range, wave height etc) could differ throughout Bahrain; this could also lead to different predicted degradation rates.

There are a number of factors relating to the macro structure of the rock may not be realistically represented in the degradation models. Both models are primarily based on aggregate tests (i.e. the samples are produced by mean of crushing the rock down to the required size) and aggregates might not have the same resistance proprieties of bigger rock used as armourstone. In particular, the presence of voids and clay intrusions is noticeable in a number of rocks in-service, whereas samples are generally clean from silt.

It is also notable that many rocks are broken during placement, which may be due in part to the method of placement and handling typically used in Bahrain, combined with weaknesses in the macro structure. It is recommended that handling and placement operations are carefully monitored and controlled, as rock breakage witnessed on sites throughout Bahrain appears to be more significant than the results of the drop test would suggest.

The reduction in the mass of individual armourstones due to weathering poses questions about the implications on the interlocking of the stones. It is expected that the reduced mass and changed shape of single rocks has a detrimental effect on the stability of the rocks and leads to an increased degree of mobility. The more the single rock elements become degraded, the more movement is allowed and the more the rock is prone to rock-to-rock abrasion and hence degradation. Thus it may be expected that weathering rates will increase over time, and the predictions (which rely on the assumption of progressive 
weathering) may not be accurate. This is particularly a concern when the models predict high levels of weathering.

One area in which there seems to be a lack of guidance is in the determination of the $\mathrm{X}_{6}$ parameter for extremely hot regions like Bahrain, where freezing temperatures never occur. The Rock Manual makes a general recommendation that the MCWI derived by Lienhart should be used to determine $\mathrm{X}_{6}$, but in the absence of freezing days this renders meteorological weathering benign. However, it is thought that the extremely hot climate accelerates spalling and crumbling of armourstone in Bahrain, and site inspections suggest that this may be a significant weathering mechanism.

For the purposes of this study $\mathrm{X}_{6}$ has been determined by the method described by Latham (1991). However, there is no local data to support this and the refinement of the $\mathrm{X}_{6}$ parameter could be the subject of further study.

It would also be beneficial to obtain actual measurements of rock degradation on Bahraini revetments against which the degradation models could be calibrated, by methods like those described in Latham's paper (1991). Such methods include block shape measurement, block surface profile monitoring and direct weight measurement.

Other ways in which confidence in these models could be greatly improved would be to undertake an expert geological assessment and petrographic analysis of the Askar quarry, and by further Micro-Deval testing.

\section{REFERENCES}

BS EN 1097-1. 2004. Tests for Mechanical and Physical Properties of Aggregates - Part 1: Determination of the Resistance to Wear (Micro-Deval). BSI, London

CIRIA, CUR, CETMEF. 2007. The Rock Manual. The Use of Rock in Hydraulic Engineering ( ${ }^{\text {nd }}$ Edition). C683, CIRIA, London

Erickson, R.L. 1993. Evaluation of Limestone and Dolomite Armor Stone Durability From Observations in the Great Lakes Region. In Rock for Erosion Control, ASTM special technical publication 1177

Latham, J.P. 1991. Degradation Model for Rock Armour in Coastal Engineering, The Geological Society, London, Quarterly Journal of Engineering Geology, 24, 101-118.

Latham, J.P., Lienhart, D., Dupray, S. 2006. Rock Quality, Durability and Service Life Prediction of Armourstone. Engineering Geology, 87 (2006) 122-140

Lienhart, D.A. 1998. Rock Engineering Rating System for Assessing the Suitability of Armourstone Sources. The Geological Society, London, Engineering Geology Special Publications 1998, v. 13, 91106

Lienhart, D.A. 2003. A Systems Approach to Evaluation of Riprap and Armor Stone Sources. The Geological Society of America, Environmental \& Engineering Geoscience, Vol. IX, No. 2, 131-149

Rangaraju, P.R. \& Edlinski, J. 2008. Comparative Evaluation of Micro-Deval Abrasion Test with Other Toughness/Abrasion Resistance and Soundness Tests. Journal of Materials in Civil Engineering, Volume 20, Issue 5, pp 343-351 